\title{
Sense of coherence: big five correlates, spirituality, and incremental validity
}

\author{
Ralph L. Piedmont ${ }^{A, B, C, D, E, F}$, Gina Magyar-Russell ${ }^{C, D, E, F}$, Nicole DiLella $^{C, E, F}$, Sondra Matter ${ }^{C, D, E, F}$
}

Loyola University Maryland, Columbia, Maryland, United States

\section{BACKGROUND}

Antonovsky (1987) developed the Sense of Coherence (SOC) scale to measure the "life orientation" that promotes an individual's ability to recognize life stressors and then effectively utilize coping resources to adjust and maintain health. Although theoretically appealing, little empirical work has been conducted to isolate the qualities of the scale that facilitate health

\section{PARTICIPANTS AND PROCEDURE}

The present study examined the factor structure of the SOC scale, as well as its incremental validity over measures of personality, spirituality, and psychological meaning in the prediction of psychosocial outcomes (e.g., hope death anxiety, life satisfaction, well-being, social support, world view). Participants consisted of 298 adults living in the United States; 98 men and 195 women (5 individuals did not disclose their gender) ages 18 to 72 (mean: 36.77 years).

\section{RESULTS}

Principal components analysis indicated that a single factor best represented the structure of the 13-item SOC scale, although this one factor explained only $31 \%$ of the total variance. The scale contained a diverse item content that was challenging to interpret personologically. The SOC scale added little explanatory variance over and above the selected covariates in the prediction of psychosocial outcomes.

\section{CONCLUSIONS}

It appears that the SOC scale represents one aspect of a larger dimension that already has other valid indicators.

\section{KEY WORDS}

sense of coherence; personality; spirituality; incremental validity; aspires; factor analysis 
Barring stressors that directly destroy the organism, people's health outcomes are unpredictable. This is the mystery the salutogenic orientation seeks to unravel. Antonovsky, 1987, p. xii

\section{BACKGROUND}

There has been movement in the health field away from focusing on negative outcomes and pathology to studying factors that promote physical and psychological health (Seligman \& Csikszentmihalyi, 2000). Antonovsky's $(1979,1987)$ salutogenic theory, that health should be viewed as movement along a continuum between total health (ease) and total ill-health (disease), exemplifies this paradigm shift. In his theory, Antonovsky (1987) proposed the concept of sense of coherence (SOC), describing it as one's ability to recognize life stressors and then effectively utilize coping resources to adjust to stressors and maintain health. To measure SOC, Antonovsky (1987) developed the Sense of Coherence scale which can be utilized in the original 29-item format as well as a 13-item short form. Both forms continue to be widely used in the scientific literature.

Ample research has shown associations between SOC and a variety of important psychosocial outcomes including greater psychological well-being (Cohen \& Savaya, 2003; Ebert, Tucker \& Roth, 2002), hope (Sharabi, Levi \& Markolat, 2012) and quality of life (Delgado, 2007), as well as lower levels of depression (Bowman, 1996; Flannery, Perry, Penk \& Flannery, 1994; Matsuura, Ohta, Kanegae, Haruda \& Ushiyama, 2003), physical and psychological distress (Feldt et al., 2007), and anxiety (Büchi et al., 1998; Gana, 2001). However, little research exists that considers the utility of the SOC scale for informing health professionals about what individuals need to preserve or improve health. Careful empirical scrutiny of health-related constructs is imperative for gaining understanding at a level that will enhance interfacing and intervening with individuals in the most efficient and effective manner (DeVellis, Alfieri \& Bala, 1995).

\section{SENSE OF COHERENCE SCALE}

Antonovsky (1987) asserted that SOC is not an individual coping style but rather an "orientation to life" that includes understanding life's stressors and events (comprehensibility), seeing stressors as adaptable through identifiable resources (manageable), and believing life is worth the utilization and application of resources (meaningfulness). Theoretically the concept of SOC is appealing to a wide range of social scientists and health professionals because it proposes that health stems from a framework of per- sonality and temperament (i.e., an orientation to life), as well as situational factors, such as personal perceptions of stressors and resources (akin to Lazarus \& Folkman's [1984] cognitive appraisal processes). Practically, further empirical examination of the content and utility of the SOC items and scale is needed in order to isolate the factors that facilitate health so that these elements might be translated into effective interventions.

Antonovsky (1993) published a paper devoted to a discussion of the structure and properties of the SOC scale. In it he reiterated from his earlier writings that the SOC scale should be interpreted as having one global factor and "that the present version of the SOC scale is not wisely used to study component inter-relations" (Antonovsky, 1987, p. 87). Since that time, however, the factor structure of the SOC continues to be debated. In an extensive systematic review of the SOC scale Eriksson \& Lindström (2005) stated that the factorial structure of the scale as it relates to the theoretical dimensions of comprehensibility, manageability, and meaningfulness is not clear. Factor analysis has confirmed the one factor solution proposed by Antonovsky in four published studies (Büchi et al., 1998; Flannery et al., 1994; Frenz, Carey \& Jorgensen, 1993; Gana, 2001), while in an equal number of studies, analyses have failed to confirm a unidimensional scale (Dudek \& Makowska, 1993; Fiorentino, 1998; Germano, Misajon \& Cummins, 2001; Larsson \& Kallenberg, 1999).

\section{CURRENT STUDY}

There is no doubt that coherence is an important element to successful adaptation. But successful adaptation is a complex process involving many different aspects of temperament (e.g., the Five-Factor Model of Personality [FFM] and Spiritual Transcendence) and behavior (e.g., perceptions regarding resources and the motivation to utilize them). By parsing out these relationships with other constructs, it may be possible for researchers in this area to better understand aspects of thriving by constructing scales that are tailored to reflect more particular aspects of coping (e.g., looking at interpersonal styles, character formation, or cognitive appraisals). While much research enthusiasm exists for this construct, some determination of what new aspects of the individual this scale assesses needs to be determined. What exactly is unique about this scale? To what extent does this scale assess constructs already available?

In an effort to document the predictive breadth of the SOC scale, it will be correlated with a number of important psychosocial outcome variables. Three broad domains will be assessed. These include aspects of the self (e.g., well-being and life satisfaction, death anxiety, sexual attitudes, positive and negative 
affect), interpersonal orientation (e.g., social support, pro-social orientation), and world view (e.g., hope, optimism, individualism-collectivism orientation). Because the SOC construct appears to assess a more global orientation of the self and its capacity to maintain a positive health orientation, it should have significant associations with all of these different types of constructs.

This study will examine the SOC scale from three perspectives. First, it will evaluate its factor structure in a general sample of American adults. As noted above, more information is needed to determine the most optimal, replicable factor structure for the instrument.

Second, this paper will evaluate how SOC relates to a number of broad individual differences dimensions that are also relevant to understanding coping and well being. Three major domains of scales have also been shown to relate to these outcomes as well. First, the domains of the Five-Factor model (FFM) of personality have also been shown to correlate with these dimensions as well (Costa \& McCrae, 1980; see Piedmont, 1998 for an overview). Sense of coherence also claims to assess aspects of personal meaning making, and the next two domains speak to this area of functioning. Second, the domain of spirituality, which is being assessed by the Assessment of Spirituality and Religious Sentiments (ASPIRES) scale was used to assess transcendent meaning making. This instrument captures an empirically robust measure of spirituality that has been shown to be independent of the FFM and to exhibit incremental validity over personality in predicting outcomes such as well-being, hope, and social support. Spirituality does represent an effort of the individual to capture a transcendent sense of meaning (Piedmont, 1999, 2009). The third domain is secular meaning making and was assessed by scales that examine personal maturity and purpose in life. These scales capture a more secular sense of meaning (McKnight \& Kashdan, 2009; Zubain, 1999). Together, these different scales represent personological qualities that should be associated with SOC. Therefore, correlations with these measures will help provide an interpretive context for SOC scores, which capture aspects of temperament, meaning making, and psychological maturity.

Finally, few studies have examined the incremental validity, the increase in predictive validity attributable to a measure (Anastasi \& Urbina, 1997), that the SOC scale provides in the prediction of health and well-being outcomes. Many of the studies that have examined the SOC scale's associations with health outcome measures have utilized zero-order correlations (see Eriksson \& Lindström, 2005 for a detailed table of findings). While zero-order correlations provide an index of the strength of association between variables, they do not provide a rigorous evaluation of a construct's unique contribution to predicting an outcome. This study will examine the extent to which scores on the SOC are independent from these measures of personality, spirituality, and psychological maturity. Questions to be addressed include, "How much variance do they share in common?", "Does the SOC capture aspects of the individual that are unique?" and "Can the SOC scale be considered a different aspect of well-being or is it merely a reformulation of these other constructs?".

\section{PARTICIPANTS AND PROCEDURE}

\section{PARTICIPANTS}

Participants consisted of 298 adults living in the United States; 98 men and 195 women (5 individuals did not disclose their gender) ages 18 to 72 (mean: 36.77 years). The majority, $81 \%$, were lay individuals while $19 \%$ were clergy or vowed religious. In terms of income levels, $50 \%$ earned between $\$ 25 \mathrm{~K}$ and $\$ 75 \mathrm{~K}$ per year, while $24 \%$ earned under $\$ 10 \mathrm{~K}$ and $16 \%$ earned over $\$ 75 \mathrm{~K}$. Eighty-two percent were Christian, while $2 \%$ were Jewish, $1 \%$ Muslim, 3\% Buddhist, 5\% Atheist/Agnostic, and 7\% "other". Concerning race, 63\% indicated Caucasian, 24\% African-American, 6\% Asian and the remaining 7\% selected either Arabic, Hispanic, or Other. Sixty-three percent were currently employed, $21 \%$ were employed part-time and $16 \%$ were not employed. Missing data are responsible for response rates totaling less than $100 \%$.

\section{MEASURES}

Sense of Coherence (SOC). Developed by Antonovsky (1987), this scale aims to assess one's sense of coherence or the global life orientation of an individual to face and adapt to life's stressors. The scale examines one's confidence from three perspectives: life is comprehensible, manageable, and meaningful. The 13-item short form was used for this study. Items are answered on a 7-point Likert-type scale with its own variable response options. Alpha reliabilities for the short form range from 0.70 to 0.92 (Eriksson \& Lindström, 2005), and retest reliability estimates are satisfactory, with a one year coefficient ranging from 0.69-0.72 (Eriksson \& Lindström, 2005). Alpha reliability in the current sample was 0.80 .

Bipolar Adjective Rating Scale (BARS). Developed by McCrae and Costa $(1985,1987)$, this 80 -item scale is designed to capture the five major dimensions of personality: Neuroticism (N), Extraversion (E), Openness (O), Agreeableness (A), and Conscientiousness (C). Research has shown this scale to capture stable, trait dimensions of personality. Responses are measured on a 1 to 7 Likert-type scale (Piedmont, 1995). Alpha reliabilities in the present sample for $\mathrm{N}, \mathrm{E}, \mathrm{O}$, A, C were $0.81,0.81,0.75,0.82$, and 0.86 , respectively. 
Assessment of Spirituality and Religious Sentiments Scale (ASPIRES). Developed by Piedmont (2010), this 9-item scale consists of three subscales: Universality (UN), Prayer Fulfillment (PF), and Connectedness $(\mathrm{CN})$. Items are answered on a 1 (Strongly Agree) to 5 (Strongly Disagree) Likert-type scale. These scales have been shown to have acceptable reliabilities: $0.83,0.87$, and 0.64 for $\mathrm{UN}, \mathrm{PF}$, and $\mathrm{CN}$, respectively. Alpha reliabilities in this sample for the PF, UN, and $\mathrm{CN}$ scales along with the overall total Spiritual Transcendence score were: $0.91,0.56,0.62$, and 0.70 , respectively. Also included is a Religious Involvement (RI) scale. Participants rate themselves on their degree of involvement in specific religion-based activities on a 1 (Never) to 7 (Several times a week) Likert-type scale. Alpha reliability for the RI scale in the current sample was 0.86 .

The Purpose in Life Test (PILT). Developed by Crumbaugh (1968), this 20-item scale measures a person's "will to meaning" as construed by Victor Frankl (1959). Responses are given on a 7-point Likert-type scale, the poles of which vary according to the question. Melton and Schulenberg (2008) reviewed studies that reported alpha coefficients ranging from 0.86 to 0.97 . Alpha reliability in this sample was 0.89 .

Self-Actualization Scale (SA). Created by Jones and Crandall (1986), this scale provides a 15-item measure of Maslow's highest level of development with response choices distributed on a 1 (Disagree) to 4 (Agree) Likert-type scale. Alpha reliability was reported at 0.65 and test-retest reliability for a 12-day interval was 0.69 (Jones \& Crandall, 1986). Alpha reliability of the scale scores in this sample was 0.88 .

State Self-Esteem Scale (SSES). Developed by Heatherton \& Polivy (1991), this 20-item scale measures self-esteem across three dimensions: academic performance, social evaluation, and appearance. Items are scored on a 5-point Likert scale from 1 (Not at all) to 5 (Extremely) with some items requiring reverse scoring. Previous studies have found the SSES to have strong construct validity and internal consistency ( $\alpha=0.92$; Heatherton \& Polivy, 1991; Linton \& Marriott, 1996). Alpha reliability for the current sample was 0.88 .

Satisfaction with Life Scale (SWLS). Developed by Diener, Emmons, Larsen \& Griffin (1985), this 5-item scale measures global assessment of life satisfaction. Items are rated on a 7-point Likert scale from 1 (Strongly disagree) to 7 (Strongly agree). Pavot and Diener (1993) reported test-retest reliabilities ranging from 0.50 to 0.84 and coefficient $\alpha$ ranging from 0.79 to 0.89 . For this study, Cronbach's $\alpha$ was 0.85 .

Bradburn Affect Balance Scale. Developed by Bradburn (1969), this 10-item, Yes/No scale captures the dimensions of positive and negative affect (PAS and NAS, respectively). Subtracting the NAS from the PAS creates the affect balance scale score. Internal consistency of the scales is generally between 0.60 and 0.75
(McDowell, 2010). Alphas for the PAS and NAS scales in this sample were 0.65 and 0.90 , respectively.

Religious Support Scale. Developed by Krause (1999), this 8-item scale measures an individual's perceived sense of support within his or her congregation among four dimensions: emotional support received, emotional support provided, negative interaction, and anticipated support. Items are rated and scored on a 4-point frequency scale ranging from 1 (Never) to 4 (Very often). Alpha reliability in the current sample was 0.79 .

Self-Report Altruism Scale. Developed by Rushton, Chrisjohn \& Fekken (1981), this 20-item scale captures altruistic behavior. Individuals rate the frequency with which they have engaged in altruistic behaviors on a 5-point Likert-type scale ranging from 1 (Never) to 5 (Very often). Rushton et al. (1981) provide $\alpha$ reliabilities in five samples ranging from 0.78 to 0.86 . Alpha reliability of this scale in the current sample was 0.91 .

Life Orientation Test Revised (LOT-R). Developed by Scheier, Carver \& Bridges (1994), the LOT is a 10-item scale designed to capture dispositional optimism with higher scores indicating more optimistic dispositions. The LOT-R is measured on a five-point Likert scale, ranging from 4 (Strongly agree) to 0 (Strongly disagree) and was found to have adequate internal consistency, $\alpha=0.78$, and excellent convergent and discriminant validity (Scheier et al., 1994). Alpha reliability in the current sample was 0.75 .

Individualism/Collectivism Scale. Developed by Dion and Dion (1991) from items originally created by Breer \& Locke (1965), this 15 -item scale is an index of how much a person values group versus individual effort, autonomy in relations with others, self-sufficiency and the impact of group membership on personal well-being. Items are answered on a 1 (Strongly agree) to 5 (Strongly disagree) Likerttype scale. Dion \& Dion (1991) reported $\alpha$ reliabilities ranging from 0.71 to 0.76 for collectivism and 0.70 to 0.65 for individualism. Alpha reliability for the overall scale in the current sample was 0.77 .

Delighted-Terrible Scale. This single item scale was developed by Andrews and Whitney (1976) as a cognitive measure of global well-being. Participants rate their overall level of life satisfaction on a visual analogue scale of 1 (Terrible) to 7 (Delighted).

Death Anxiety Scale (DAS). Developed by Templer (1970), the DAS is a 15-item scale that measures an individual's level of affective arousal in relation to death awareness. In this study, a True/False format of the scale was used. Previous studies found an internal consistency coefficient of 0.76 (Templer, 1970; McMordie, 1979). Alpha reliability for this scale in the current sample was 0.59 .

Hope Scale. Developed by Snyder et al. (1996), this 6-item scale captures two dimensions of hope: agency and pathways. Participants rate the extent to which 
they agree with each item on an 8-point Likert scale from 1 (Definitely false) to 8 (Definitely true). Snyder et al. (1996) reported internal consistency coefficients ranging from 0.82 to 0.95 and strong construct and discriminant validity. Alpha reliability in the current sample was 0.83 .

Sexual Opinion Survey (SOS). This 21-item scale was developed by Fisher, Byrne, White \& Kelley (1988) to capture attitudes about sexuality. Two dimensions, erotophobia, reflecting negative attitudes about sexual behaviors, and erotophilia, positive attitudes towards sexual activities and behaviors are measured. Items are responded to on a 7-point Likert scale ranging from 1 (Strongly agree) to 7 (Strongly disagree). Alpha reliability in the current sample for Erotophilia was 0.82 and for Erotophobia it was 0.85 .

Other variables of interest were assessed in this study using single-item questions to gather information about age, race, gender, religious affiliation, marital status, and level of income.

\section{PROCEDURE}

Participants were recruited trough convenience sampling. Each researcher invited individuals to participate by administering paper and pencil surveys. The order of scales within each packet was randomized to control for potential order effects. Participants were instructed to complete the scales in the order in which they appeared. Once completed, materials were placed back in the original envelope and returned to the researcher who recruited them. No remuneration for participation was provided.

Table 1

Factor loadings and descriptive statistics for the Sense of Coherence (SOC) scale

\begin{tabular}{cc}
\hline SOC item & Factor loading \\
\hline Item 1 & 0.48 \\
Item 2 & 0.37 \\
Item 3 & 0.56 \\
Item 4 & 0.51 \\
Item 5 & 0.59 \\
Item 6 & 0.49 \\
Item 7 & 0.66 \\
Item 8 & 0.65 \\
Item 9 & 0.68 \\
Item 10 & 0.61 \\
Item 11 & 0.42 \\
Item 12 & 0.71 \\
Item 13 & 0.31 \\
Mean & 59.46 \\
$\alpha$ & 11.08 \\
Standard deviation & 0.80
\end{tabular}

Note. $N=298$.

\section{RESULTS}

\section{FACTOR STRUCTURE}

The items of the Coherence scale were subjected to a principal components analysis in order to determine the underlying structure to the scale. The scree plot indicated that from one to four factors could be extracted (first 6 eigenvalues were: 3.98, 1.32, 1.08, 1.07, $0.93,0.89)$. The two, three, and four factor solutions were not found suitable due to the presence of factors that were defined by only one or two items. The one factor solution appeared the most appropriate (explaining $31 \%$ of the total variance), both statistically and interpretively. Factor loadings are presented in Table 1 . As can be seen, all items loaded significantly on this single dimension, an outcome noted in other studies. Alpha reliability for this single dimension was quite high $(\alpha=0.80)$. Total scores were found to be normally distributed, and the overall mean and standard deviation were consistent with values found in other studies (e.g., Antonovsky, 1993). This total score will be used in all further analyses.

\section{OVERLAP WITH PERSONALITY, SPIRITUALITY, AND MEANING}

The Coherence total score was correlated with three domains of variables: the dimensions of the FFM, Spiritual Transcendence and Religious Involvement, and measures of psychological growth/maturity. These results are presented in Table 2. As can be seen, Coherence correlated significantly with four of the five FFM dimensions. A regression analysis linking the FFM domains to coherence indicated that the

\section{Table 2}

Correlations between the Sense of Coherence (SOC) scale and measures of personality, spirituality, and existential meaning

\begin{tabular}{cc}
\hline Predictor & SOC scale \\
\hline Neuroticism & $-0.62^{* * *}$ \\
Extraversion & $0.35^{* * *}$ \\
Openness to Experience & -0.03 \\
Agreeableness & $0.40^{* * *}$ \\
Conscientiousness & $0.44^{* * *}$ \\
Prayer Fulfillment & $0.27^{* * *}$ \\
Universality & $0.16^{* *}$ \\
Connectedness & $0.15^{* *}$ \\
Total Spiritual Transcendence & $0.28^{* * *}$ \\
Religious Involvement & 0.00 \\
Purpose in Life & $0.70^{* * *}$ \\
Self-Actualization & $0.52^{* * *}$
\end{tabular}

Note. $N=263$ $p<0.05,{ }^{* *} p<0.01,{ }^{* * *} p<0.001$, two-tailed 
two sets of constructs were highly related, $R=0.70$, $R^{2}=0.49, F(5,257)=49.08, p<0.001$. In this analysis, only $\mathrm{N}(\beta=-0.49), \mathrm{E}(\beta=0.25)$, and $\mathrm{C}(\beta=0.14)$ were significantly related to Coherence.

Correlations with scores from the ASPIRES scales indicated that Coherence was related to all aspects of Spiritual Transcendence but did not relate to Religious involvement. This pattern of associations indicates that those scoring high on Coherence have created for themselves a very broad sense of personal meaning within the context of some transcendent reality. They tend to view all life as interconnected and organized, and the process of life unfolds in accord with some larger plan. They also feel embedded in community and form strong relationships with others. Interestingly, there is no association with involvement in any formal religious community. Thus, while there is a broad understanding of life and engagement with it, such understandings may or may not be channeled through established religious communities. To better understand Coherence's relations with spirituality, a hierarchical regression analysis was conducted. On step 1, the FFM personality domains were entered. On step 2 the ASPIRES scales. The ASPIRES scales significantly increased the explained variance in Coherence, $\Delta R^{2}=0.04$, partial $F(4,253)=5.74, p<0.001$. In this analysis, Prayer Fulfillment $(\beta=0.20)$, Connectedness $(\beta=0.10)$, and Religious Involvement $(\beta=-0.14)$ emerged as the significant predictors. In this analysis Religious Involvement is negatively associated with Coherence, indicating that the broad sense of spirituality is not focused through, or related to, any type of formal religious tradition.

Finally, Coherence was correlated with measures of maturity and meaning, and high levels of association were noted. The correlation with scores on the Purpose in Life test $[r(261)=0.70, p<0.001]$ is almost as high as the Coherence scale's reliability. This suggests the possibility of collinearity between these two measures. To better gauge overlap, the hierarchical regression reported above was extended to include these two measures on the final step of the analysis. These two scales significantly increased the predictive variance over both the FFM and spirituality scales, $\Delta R^{2}=0.13$, partial $F(2,251)=47.49$, $p<0.001$. Both the PILT $(\beta=0.39)$ and SA $(\beta=0.26)$ scales contributed significantly. Overall, all 11 scales accounted for $66 \%$ of the variance in SOC $[R=0.81$, $F(11,251)=44.25, p<0.001]$.

The SOC scale evidences a tremendous amount of overlap with these established measures of personality, spirituality, and meaning/maturity. In fact, $84 \%$ of the reliable variance of the SOC scale is shared with these predictors (i.e., overall $R^{2}$ divided by $\alpha$ ). Thus, there is very little uniquely reliable variance contained in the SOC $\left(14 \%: \alpha-R^{2}\right)$, which is less than the amount of error variance $(20 \%: 1-\alpha)$. Usually, when the amount of uniquely reliable variance is less than the overall amount of error variance a scale is not seen as having sufficient uniquely reliable variance to warrant its separate interpretation. Thus, a consideration of the incremental validity of the SOC is warranted.

\section{INCREMENTAL PREDICTIVE VALIDITY}

Table 3 presents the correlations between the SOC and a variety of psychosocial constructs. Column 2 presents the simple zero-order associations. As can be seen SOC is significantly related to 11 of the 13 constructs. The strongest associations are with elements of resilience and well-being [e.g., with Hope: $r(260)=0.53, p<0.001$; Self-Esteem: $r(260)=0.66$, $p<0.001$; and Satisfaction with Life: $r(260)=0.51$, $p<0.001]$. Moderate associations were found for the affect constructs [e.g., Positive Affect $r(260)=0.34$, $p<0.001$; Negative Affect $r(260)=-0.47, p<0.001$ ] The average level of association over these 13 constructs was $r=0.34$.

Column 3 presents partial correlations between SOC and these outcomes controlling for the spiritual and religious scales from the ASPIRES. As can be seen, spirituality does not mediate SOC's relations to these outcomes, the mean $r$ being reduced to 0.32 . Column 4 presents SOC's associations controlling for both the FFM personality domains and spirituality. Clearly, personality partially mediates SOC's relations to all of these outcomes. Social Support and Prosocial Orientation appear significantly mediated by personality. The overall average partial correlation was reduced by one magnitude of order, $r=0.20$. Column 5 presents the partial correlations that control for the previous nine variables plus PILT and SA. As can be seen, the scales completely mediate five relationships and partially mediate 2 others (Optimism seems unaffected while the relationship with Individualism is enhanced). The mean correlation is another magnitude of order lower, mean $r=0.11$. Consistent with the findings from above, the predictive breadth and strength of association between the SOC scale and other constructs is significantly reduced when the influence of the personality, spirituality, and meaning/maturity constructs are removed.

\section{DISCUSSION}

Overall the SOC construct, while evidencing a unitary dimension, is indeed a complex construct. The single factor only accounted for $31 \%$ of the total variance indicating that the items may have limited homogeneity. Correlations with the FFM showed SOC to represent a broad dimension of coping ability, supporting the construct validity of the scale. 
Ralph L. Piedmont, Gina Magyar-Russell, Nicole DiLella, Sondra Matter

Table 3

Zero-order and partial correlations between Sense of Coherence (SOC) scale and psychosocial outcome measures

\begin{tabular}{ccccc}
\hline Outcome & Zero-Order $r^{\mathrm{a}}$ & Partial $r-1^{\mathrm{b}}$ & Partial $r-2^{\mathrm{c}}$ & ${\text { Partial } r-3^{\mathrm{d}}}^{\text {(n) }}$ \\
\hline Death Anxiety & $-0.36^{* * *}$ & $-0.36^{* * *}$ & $-0.19^{* *}$ & -0.10 \\
Social Support & $-0.17^{* *}$ & -0.12 & -0.06 & 0.01 \\
Erotophilia & -0.11 & -0.08 & -0.02 & 0.05 \\
Erotophobia & $0.16^{* *}$ & $0.18^{* *}$ & 0.09 & 0.04 \\
Hope & $0.53^{* * *}$ & $0.52^{* * *}$ & $0.30^{* * *}$ & 0.07 \\
Satisfaction with Life & $0.51^{* * *}$ & $0.51^{* * *}$ & $0.27^{* * *}$ & 0.07 \\
Optimism & -0.09 & -0.06 & $0.20^{* *}$ & $0.20^{* * *}$ \\
Delighted-Terrible & $0.50^{* * *}$ & $0.52^{* * *}$ & $0.31^{* * *}$ & 0.13 \\
Positive Affect & $0.34^{* * *}$ & $0.28^{* * *}$ & $0.14^{*}$ & -0.01 \\
Negative Affect & $-0.47^{* * *}$ & $-0.44^{* * *}$ & $-0.24^{* * *}$ & $-0.18^{* *}$ \\
Self-Esteem & $0.66^{* * *}$ & $0.65^{* * *}$ & $0.38^{* * *}$ & $0.26^{* * *}$ \\
Prosocial Orientation & $0.18^{* *}$ & $0.16^{* *}$ & 0.09 & 0.01 \\
Individualism & $-0.32^{* * *}$ & $-0.28^{* * *}$ & $-0.29^{* * *}$ & $-0.34^{* * *}$ \\
Mean $r$ & 0.34 & 0.32 & 0.20 & 0.11 \\
\hline
\end{tabular}

Note. Partial $r-1$ controls for the four scales from the ASPIRES; Partial $r-2$ controls for the four scales from the ASPIRES plus the Big Five domains; Partial $r-3$ controls for the previous nine scales plus Purpose in Life and Self-Actualization scores. $p<0.05,{ }^{* *} p<0.01,{ }^{* * *} p<0.001$, two-tailed.

${ }^{\mathrm{a}} N=262 ;{ }^{\mathrm{b}} N=250 ;{ }^{\mathrm{c}} N=234 ;{ }^{\mathrm{d}} N=234$.

Individuals scoring high on SOC evidence a strong sense of well-being, a positive social orientation characterized by high levels of social engagement, altruism, compassion, and social justice. The significant correlations with four of the five personality domains underscore the factorial complexity of this scale. The pattern of relations with $\mathrm{N}$ and $\mathrm{E}$ indicate that those scoring high on coherence have a strong sense of emotional stability and well-being, cope well with stress, and have an optimistic view of life. The positive associations with $\mathrm{A}$ and $\mathrm{C}$ reflect individuals who have an altruistic orientation; they can channel their efforts to the service of others. Also, high levels of $\mathrm{A}$ and $\mathrm{C}$ are also associated with strong coping skills. The lack of an association with Openness replicates other correlational findings in the literature. Nonetheless, this orthogonality appears inconsistent with the concept of coherence as well as with several of the items on the scale. Seven of the 13 items included the word "feelings" as part of the question (e.g., "does it happen that you have feelings inside that you would rather not feel?"). Yet, aspects concerning the permeability of one's inner world do not find expression in the scale. While high scorers on the SOC may be adaptive and compassionate, they may also lack both empathy for others and creativity in finding solutions to problems.

Scores on the SOC were also significantly, though modestly, related to aspects of Spiritual Transcendence, further underscoring the altruistic orientation of high scorers on this scale. High SOC scorers appear to understand life in more unitive terms; there are connections and relationships among all aspects of life, which may find a common origin and ending in some transcendent reality. Interestingly, scores on the SOC were independent of any type of religious involvement. Thus, high scores on the SOC reflect individuals who may see themselves as spiritual, but not religious. However, the magnitude of these associations is small, indicating that transcendent meaning making is only tangentially related to SOC. As will be elaborated below, SOC appears more oriented towards a secular-type of meaning making.

While much attention has been given to the concept of coherence as an important aspect of salutogenesis, correlations with measures of psychological maturity and meaning demonstrate that SOC is not a unique construct. The PIL scale also attempts to examine the extent to which an individual has created a personal sense of meaning and direction in his/her life, something very similar to what SOC is measuring. The 0.70 correlation between these two measures raises questions of redundancy between the two scales. If PIL and SOC are indicators of the same underlying construct, then the amount of variance these two scales share in common is $70 \%$ (see Ozer, 1985). With reliabilities of 0.89 and 0.80 , respectively, that means that the SOC scale shares $88 \%$ of its reliable variance with PIL. The question emerges, does the SOC has sufficient uniquely reliable variance to warrant separate interpretation from the PIL?

Examining the partial correlations in Table 3, they demonstrated that once the FFM, ASPIRES, and PIL/ SA scales were removed, the SOC had limited relatedness to the outcome variables. Rather than debating whether or not these findings support the utility of the SOC or not, it may be more expeditious to argue that SOC represents one aspect of a larger dimension that already has other valid indicators. It may behoove future researchers to understand 
this dimension of psychological meaning/maturity by employing multiple measures of the construct. Bringing in measures of meaning and maturity may help foster theory development and provide greater explanatory depth to findings.

As it stands, the SOC scale contains a diverse item content that is challenging to interpret structurally. Such complexity makes it difficult to interpret findings psychologically. What are the personal and situational factors that promote or hinder salutogenesis? What are the elements involved in this process? As the results of this study demonstrated, SOC shares much in common with individual differences in trait personality and meaning making/psychological maturity. Knowing that there are higher aspects of human functioning that create the potential for thriving is important. However, knowing what contributes to this process and how it can be accomplished are the more "nuts and bolts" questions that can only be answered by appeal to broader models of temperament, character, and appraisal processes. This study provides a step towards systematically unraveling the complex process of adaptation.

\section{References}

Anastasi, A. \& Urbina, S. (1997). Psychological testing ( $7^{\text {th }}$ ed.). Englewood Cliffs, NJ: Prentice-Hall.

Andrews, F.M. \& Withey, S.B. (1976). Social indicators of well-being: American's perceptions of life quality. New York: Plenum.

Antonovsky, A. (1979). Health, Stress, and Coping: New Perspectives on Mental and Physical Well-Being. San Francisco, CA: Jossey-Bass.

Antonovsky, A. (1987). Unravelling the mystery of healthy. San Francisco, CA: Jossey-Bass.

Antonovsky, A. (1993). The structure and properties of the sense of coherence scale. Social Science Medicine, 36, 725-733.

Bowman, B.J. (1996). Cross-cultural validation of Antonovsky's sense of coherence scale. Journal of Clinical Psychology, 52, 547-549.

Bradburn, N.M. (1969). The structure of psychological well-being. Chicago, IL: Aldine.

Breer, P.E. \& Locke, E.A. (1965). Task experience as a source of attitudes. Homewood, IL: Dorsey Press.

Büchi, S., Sensky, T., Allard, S., Stoll, T., Schnyder, U., Klaghofer, R. \& Buddeberg, C. (1998). Sense of coherence - a protective factor for depression in rheumatoid arthritis. Journal of Rheumatology, 25, 869-875.

Cohen, O. \& Savaya, R. (2003). Sense of coherence and adjustment to divorce among Muslim Arab citizens of Israel. European Journal of Personality, 17, 309-326.

Costa, P.T. \& McCrae, R.R. (1980). Influence of extraversion and neuroticism on subjective well-being:
Happy and unhappy people. Journal of Personality and Social Psychology, 38, 668-678.

Crumbaugh, J. (1968). Cross-validation of purposein-life test based on Frankl's concepts. Journal of Individual Psychology, 24, 74-81.

Delgado, C. (2007). Sense of coherence, spirituality, stress and quality of life in chronic illness. Journal of Nursing Scholarship, 39, 229-234.

DeVellis, R.F., Alfieri, W.S.A. \& Bala, I. (1995). The importance of careful measurement in health education research, theory and practice. Health Education Research, 10, 1-7.

Diener, E., Emmons, R.A., Larsen, R.J. \& Griffin, S. (1985). The satisfaction with life scale. Journal of Personality Assessment, 49, 71-75.

Dion, K.K. \& Dion, K.L. (1991). Psychological individualism and romantic love. Journal of Social Behavior and Personality, 6, 17-33.

Dudek, B. \& Makowska, Z. (1993). Psychometric characteristics of the orientation to life questionnaire for measuring the sense of coherence. Polish Psychological Bulletin, 24, 309-318.

Ebert, S.A., Tucker, D.C. \& Roth, D.L. (2002). Psychological resistance factors as predictors of general health status and physical symptom reporting. Psychology, Health and Medicine, 7, 363-375.

Eriksson, M. \& Lindström, B. (2005). Validity of Antonovsky's sense of coherence scale: A systematic review. The Journal of Epidemiology and Community Health, 59, 460-466.

Feldt, T., Lintula, H., Suominen, S., Koskenvuo, M., Vahtera, J. \& Kivimaki, M. (2007). Structural validity and temporal stability of the 13-item sense of coherence scale: Prospective evidence from the population-based HeSSup study. Quality of Life Research, 16, 483-493.

Fiorentino, L.M. (1998). Sense of coherence and the stress-illness relationship among employees: a prospective study. In: H.I. McCubbin, T.E. Thompson \& A.L. Thompson et al. (eds.). Stress, coping, and health in families. Sense of coherence and resiliency (pp. 91-106). Thousand Oakes, CA: Sage.

Fisher, W.A., Byrne, D., White, L.A. \& Kelley, K. (1988). Erotophobia-erotophilia as a dimension of personality. Journal of Sex Research, 25, 123-151.

Flannery, R.B., Perry, J.C., Penk, W.E. \& Flannery, G.J. (1994). Validating Antonovsky's sense of coherence scale. Journal of Clinical Psychology, 50, 575577.

Frankl, V. (1959). Man's search for meaning. Boston, MA: Beacon.

Frenz, A.W., Carey, M.P. \& Jorgensen, R.S. (1993). Psychometric evaluation of Antonovsky's sense of coherence scale. Psychological Assessment, 5, 145-153.

Gana, K. (2001). Is sense of coherence a mediator between adversity and psychological well-being in adults? Stress and Health, 17, 77-83. 
Germano, D., Misajon, R. \& Cummins, R.A. (2001). Quality of life and sense of coherence in people with arthritis. Journal of Clinical Psychology in Medical Settings, 8, 253-261.

Heatherton, T.F. \& Polivy, J. (1991). Development and validation of a scale for measuring state self-esteem. Journal of Personality and Social Psychology, 60, 895-910.

Jones, A. \& Crandall, R. (1986). Validation of a short index of self-actualization. Personality and Social Psychology Bulletin, 12, 63-73.

Krause, N. (1999). Religious Support. Multidimensional measurement of religiousness/spirituality for use in health research. Retrieved 2012 June 27 from http://www.fetzer.org/research/248-dses.

Larsson, G. \& Kallenberg, K. (1999). Dimensional analysis of sense of coherence using structural equation modelling. European Journal of Personality, 13, 51-61.

Lazarus, R.S. \& Folkman, S. (1984). Stress, Appraisal, and Coping. New York: Springer Publishing Company.

Linton, K.E. \& Marriott, R.G. (1996). Self-esteem in adolescents: Validation of the state self-esteem scale. Personality and Individual Differences, 21, 85-90.

Matsuura, E., Ohta, A., Kanegae, F., Haruda, Y. \& Ushiyama, O. (2003). Frequency and analysis of factors closely associated with the development of depressive symptoms in patients with scleroderma. Journal of Rheumatology, 30, 1782-1787.

McCrae, R.R. \& Costa, P.T., Jr. (1985). Updating Norman's Adequate Taxonomy: Intelligence and personality dimensions in natural language questionnaires. Journal of Personality and Social Psychology, 49, 710-721.

McCrae, R.R. \& Costa, P.T., Jr. (1987). Validation of the five-factor model of personality across instruments and across observers. Journal of Personality and Social Psychology, 52, 81-90.

McDowell, I. (2010). Measures of self-perceived wellbeing. Journal of Psychosomatic Research, 69, 69-79.

McKnight, P.E., \& Kashdan, T.B. (2009). Purpose in life as a system that creates and sustains helaht and well-being: An integrative, testable theory. Review of General Psychology, 13, 242-251.

McMordie, W.R. (1979). Improving measurement of death anxiety. Psychological Reports, 44, 975-980.

Melton, A.M.A. \& Schulenberg, S.E. (2008). On the measurement of meaning: Logotherapy's empirical contributions to humanistic psychology. The Humanistic Psychologist, 36, 31-44.

Ozer, D.J. (1985). Correlation and the coefficient of determination. Psychological Bulletin, 97, 307-315.

Pavot, W. \& Diener, E. (1993). Review of the satisfaction with life scale. Psychological Assessment, 5, 164-172.

Piedmont, R.L. (1995). Big five adjective marker scales for use with college students. Psychological Reports, 77, 371-378.
Piedmont, R.L. (1998). The Revised NEO Personality Inventory: Clinical and Research Applications. New York: Plenum Press.

Piedmont, R.L. (1999). Does spirituality represent the sixth factor of personality? Spiritual transcendence and the five-factor model. Journal of Personality, 67, 983-1013.

Piedmont, R.L. (2001). Spiritual transcendence and the scientific study of spirituality. Journal of Rehabilitation, 67, 4-14.

Piedmont, R.L. (2009). The contribution of religiousness and spirituality to subjective well-being and satisfaction with life. In: L.J. Francis (ed.). International Handbook of Education for Spirituality, Care and Well-being (pp. 89-105). New York: Springer.

Piedmont, R.L. (2010). Assessment of Spirituality and Religious Sentiments, technical manual ( $2^{\text {nd }}$ ed.). Timonium, MD: Author.

Rushton, J.P., Chrisjohn, R.D. \& Fekken, G.C. (1981). The altruistic personality and the self-report altruism scale. Personality and Individual Differences, 2, 293-302.

Scheier, M.F., Carver, C.S. \& Bridges, M.W. (1994). Distinguishing optimism from neuroticism (and trait anxiety, self-mastery, and self-esteem): A reevaluation of the life orientation test. Journal of Personality and Social Psychology, 67, 1063-1078.

Seligman, M.E.P. \& Csikszentmihalyi, M. (2000). Positive psychology: An introduction. American Psychologist, 55, 5-14.

Sharabi, A., Levi, U. \& Markolat, M. (2012). Children's loneliness, sense of coherence, family climate, and hope: Developmental risk and protective factors. The Journal of Psychology, 146, 61-83.

Snyder, C.R., Sympson, S.C., Ybasco, F.C., Borders, T.F., Babyak, M.A. \& Higgins, R.L. (1996). Development and validation of the state hope scale. Journal of Personality and Social Psychology, 70, 321-335.

Templer, D.L. (1970). The construction and validation of a death anxiety scale. Journal of General Psychology, 82, 165-177.

Zubain, M.Z. (1999). The relationship between meaning in life and mental well-being. South African Journal of Psychology, 29, 36-41. 